\title{
Processing and evaluation of osmodried mango slices - A micronutrient rich food
}

\author{
-G. Gurumeenakshi ${ }^{1 *}$ and N. Varadharaju ${ }^{2}$ \\ ${ }^{1}$ Centre for Post Harvest Technology, Agricultural Engineering College and Research Institute, Tamil Nadu Agricultural University, \\ Coimbatore (T.N.) India \\ ${ }^{2}$ Agricultural Engineering College and Research Institute (T. N.A.U.) Coimbatore (T.N.) India \\ Email : gurumeenakshi@rediffmail.com; nvaradharaju@yahoo.com
}

SUMMARY :

Osmotic dehydration is a novel technique for the production of shelf stable, nutritious and tasty products. Mango is a fruit which is highly relished in both raw and processed form. Various studies have indicated that pretreatment of fruits prior to osmotic dehydration improved the quality of the product. Hence, an attempt was made to study the effect of various pretreatments in the quality characteristics of osmo dried fruits. Two varieties of mango namely Bangalora and Pairi were selected for the study. The fruits were washed, peeled, destoned and cut to slices. The slices were given four pretreatments viz., soaking the fruit slices in a solution of citric acid, citric acid + KMS, ascorbic acid and ascorbic acid + KMS for $30 \mathrm{~min}$. After pretreatment the fruit slices were soaked in the osmotic agent (sugar syrup) for $18 \mathrm{~h}$ followed by dehydration, cooling and packing. The dried fruit slices were packed in metallised polypropylene packs and subjected to shelf-life studies for a period of 180 days. Analysis of the physio-chemical qualities, microbial and sensory qualities of the fruit slices during storage, indicated that the osmo dried fruit samples pretreated with ascorbic acid +KMS and citric acid + KMS had retained highly acceptable qualities.

KEY WORDS : Mango, Pretreatment, Osmotic agent, Dehydration

How to cite this paper: Gurumeenakshi. G. and Varadharaju, N. (2018). Processing and evaluation of osmodried mango slices - A micronutrient rich food. Internat. J. Proc. \& Post Harvest Technol., 9 (2) : 39-43. DOI: 10. 15740/HAS/IJPPHT/9.2/39-43. Copyright@ 2018: Hind Agri-Horticultural Society. 